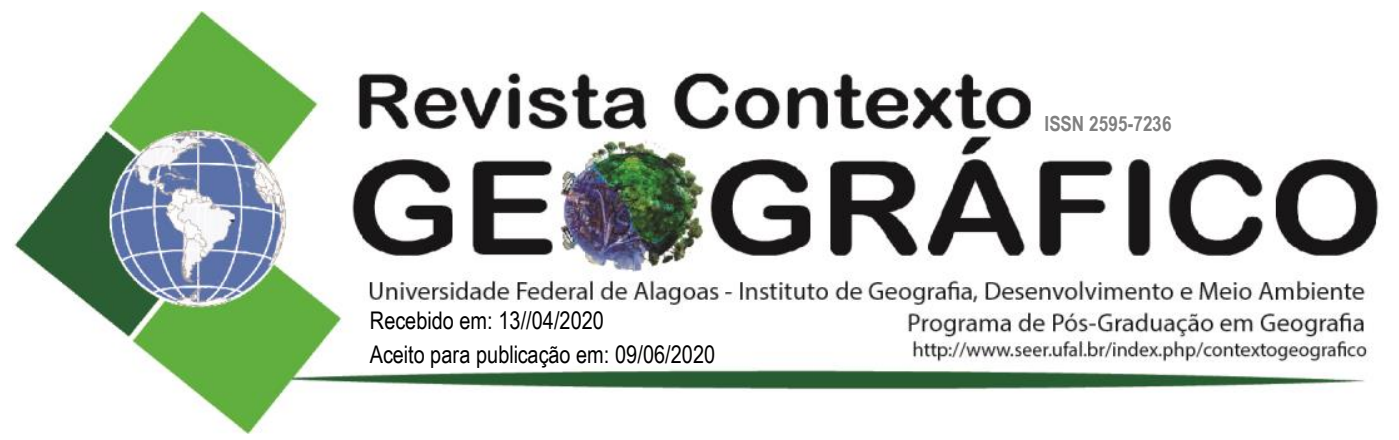

\title{
REVISITANDO AUTORES SOBRE OS CONCEITOS DE SEGREGAÇÃO SOCIOESPACIAL E EXCLUSÃO SOCIAL NA ANÁLISE DA PRODUÇÃO DESIGUAL DO ESPAÇO URBANO
}

\author{
Luciane Maranha de Oliveira Marisco \\ Professora do Instituto de Geografia, Desenvolvimento e Meio Ambiente e do Programa de Pós- \\ graduação em Geografia-PPGG/UFAL, AL, Brasil \\ luciane.marisco@igdema.ufal.br
}

\begin{abstract}
RESUMO - Este artigo teve por objetivo resgatar alguns autores ao longo das publicações acadêmicas acerca dos conceitos de segregação socioespacial e exclusão social. Remete a importância de uma reflexão de tais conceitos, de modo a sua adequada aplicação na academia por discentes e docentes. A metodologia consistiu de uma revisão bibliográfica com base em livros, artigos, dissertações e teses disponíveis nas diversas plataformas (digitais e físicas). Esta revisão possibilitou uma maior clareza teórico-conceitual permitindo assim sua adequada utilização nas diversas pesquisas que visam aprofundar nestas temáticas .
\end{abstract}

Palavras-chave: Segregação espacial; Exclusão; Espaço urbano.

\section{REVISITING AUTHORS ABOUT THE CONCEPTS OF SOCIO-SPATIAL SEGREGATION AND SOCIAL EXCLUSION IN THE ANALYSIS OF UNEQUAL PRODUCTION IN URBAN SPACE}

\begin{abstract}
This article aimed to rescue some authors throughout academic publications about the concepts of socio-spatial segregation and social exclusion. It refers to the importance of reflecting on such concepts, so that they can be properly applied in the academy by students and teachers. The methodology consisted of a bibliographic review based on books, articles, dissertations and theses available on different platforms (digital and physical). This review enabled greater theoretical-conceptual clarity, thus allowing its proper use in the various researches that aim to deepen these themes.
\end{abstract}

Keywords: Spatial segregation; Exclusion; Urban space.

\section{INTRODUÇÃO}

Desde a década de oitenta do século XX tem-se o debate nos meios acadêmicos e em outras esferas (poder público, ONGs, etc.) acerca dos processos de segregação socioespacial e exclusão social, e seus impactos na sociedade como um todo. O processo de globalização que tomou impulso na década de 1980, primeiro nos países do primeiro mundo - Inglaterra e Estados Unidos, e depois se estendendo a outros países tem promovido uma redefinição de princípios e valores no campo econômico, político, social e cultural. Dentre alguns dos efeitos promovidos por essa globalização, podemos perceber, por um lado, o aumento significativo da exclusão social entendido como um processo associado a perdas gradativas dos direitos fundamentais a todo ser humano (o direito à saúde, à educação, à habitação, ao emprego, aos 
direitos civis, aos direitos políticos etc.,), enfim, aos direitos garantidos pela Declaração Universal dos Direitos Humanos de 1948. Por sua vez, o impacto da globalização sob os processos de reestruturação da economia e no padrão de estruturação das cidades vem acentuando a segregação e a exclusão resultando em um tecido urbano cada vez mais desigual.

Este artigo tem por objetivo revisitar alguns teóricos dos estudos urbanos, que se ocuparam em entender as lógicas que regem tais dinâmicas, assim como elaborando conceitos que definissem melhor estes processos nas diversas escalas geográficas. Começamos por afirmar que processos de segregação reforçam os de exclusão, uma vez que a concentração de excluídos em determinadas áreas da cidade, tem consolidado a segregação desses grupos e o inverso também é verdadeiro.

O conceito de segregação socioespacial que estamos considerando nessa reflexão é a separação no espaço da população por classes de renda, raça, etnia, ocupação socioprofissional, entre outras variáveis, configurando espaços homogêneos no interior do tecido urbano baseado em (CASTELLS, 2000). No sentido restrito a segregação socioespacial pressupõe a separação intencional de um grupo de classes ou fração de classes em relação a outros segmentos sociais menos favorecidos com objetivos nítidos de discriminação. É com base nesse entendimento que adotamos esse conceito para essa reflexão. Por sua vez, o conceito de exclusão social é aqui adotado no seu sentido amplo, em que se relaciona a um conjunto de perdas não somente relacionadas a razão econômica, mas inclui perdas também no campo social, afetivo, familiar, político e inclusive territorial no qual nos baseamos em (COSTA,1997; PAUGAM ,1999; PECHMAN, 2002) entre outros teóricos.

Essa reflexão visa um entendimento desses processos não como dinâmicas autônomas, pois segregação e exclusão são faces da mesma moeda em função não apenas da distribuição desigual dos investimentos urbanos (infraestrutura e equipamentos sociais) na cidade, mas também das rendas entre os sujeitos. Por sua vez, como assinala (SANTOS,1994) a permanência dessa desigual apropriação do conjunto de benefícios urbanos produzidos coletivamente, mas apropriados seletivamente ratifica uma condição a nosso ver de exclusão social, territorial e de segregação espacial daí esses dois conceitos inter-relacionados.

A exclusão social se traduz na negação ao indivíduo do acesso à educação, à saúde, ao lazer, a segurança, a cidadania, aos direitos políticos, a habitação, a ambientes salubres, a moradias que atendam os requisitos mínimos de conforto, higiene e segurança, previstos nas normativas urbanísticas, enfim, do que (LEFEBVRE, 2001) colocou como o direito à cidade. Se por um lado, esses fenômenos conjugados têm se manifestado cada vez mais no processo de urbanização mundial, e em particular na brasileira, é preciso entender com que características se efetivam no espaço urbano brasileiro. A lógica que presidiu o processo de desenvolvimento econômico sob o modo de produção capitalista nos países periféricos, promoveu uma intensa repartição desigual da renda com impactos negativos sobre as diferentes classes sociais. Uma concentração da riqueza para uma pequena camada da população em oposição a uma disseminação da pobreza. Uma leitura na perspectiva geográfica permite-nos delinear com precisão os impactos desse processo nas cidades brasileiras. Milton Santos figura entre os geógrafos que se ocuparam em entender e explicar o processo de urbanização nos países subdesenvolvidos com grandes contribuições no entendimento das dinâmicas e lógicas que regem a reprodução das cidades brasileiras. Hoje o Brasil é um país com intensas disparidades inter-regionais, interurbanas e intraurbanas.

O que explica tais disparidades? $\mathrm{O}$ entendimento da questão urbana tal qual se apresenta na realidade brasileira tem sua origem na Lei de Terras de 1850, quando se institucionaliza a propriedade privada da terra, em que somente através da compra torna-se possível a aquisição de um lote. A terra torna-se mercadoria e seu acesso somente se dá através do poder de compra, dessa forma excluindo uma grande parcela da população do direito à terra. A essas medidas, soma-se ao longo de séculos as ações do poder público em seus diversos níveis escalares 
(federal, estadual e municipal) e dos diversos agentes produtores do espaço urbano os quais nos remete (CORREAA,1989), como os proprietários fundiários, os promotores imobiliários, os proprietários dos meios de produção, as agências financiadoras, que tem impresso durante décadas um padrão de uso e ocupação do solo urbano extremamente perverso. Os efeitos espaciais destas lógicas capitalistas é a acentuação da segregação urbana e da exclusão social. Como entendê-las à luz das teorias urbanas é o que se apresenta a seguir.

\title{
APORTES TEÓRICOS AO CONCEITO DE SEGREGAÇÃO SOCIOESPACIAL
}

Buscando a etimologia da palavra, segregar é o ato de separar, isolar, evitar aproximação, pôr-se à margem. A segregação urbana remete a dois tipos de segregação: a segregação involuntária e a voluntária (SPOSITO, 1996). Os fenômenos de segregação urbana precisam ser entendidos de modo amplo, pois diz respeito tanto a um conjunto de ações e políticas urbanas (seja uma política por parte do setor privado, do setor público, ou em conjunto), estabelecendo espaços diferenciados na cidade no que se refere o acesso à terra, a infraestrutura e equipamentos urbanos distribuídos desigualmente, quanto a segregação por raça, etnia, religião etc. No Brasil devido nosso histórico de desigualdade socioeconômica, a segregação por renda é a que mais se destaca. Desse modo a segregação involuntária precisa ser analisada em suas diversas dimensões (econômica, cultural etc.). Por outro lado, a voluntária diz respeito a um ato voluntário de um indivíduo ou segmento de classe visando à separação intencional de outras classes estabelecendo a auto segregação, onde os condomínios e loteamentos fechados constituem a melhor expressão e que no modelo societário atual constitui um estilo de vida e de moradia para alguns. Para entender melhor esse conceito e sua análise, alguns teóricos que tem se ocupado de entender estes processos e lógicas serão aqui apresentados. Para PECHMAN o urbanismo no Brasil sempre recebeu influências do urbanismo produzido no exterior assim assinala que:

\begin{abstract}
Numa sociedade que não reconhecia a questão social, o urbanismo não teve o mesmo papel reformador que experimentou na Europa e nos Estados Unidos, abrindo caminho para os excluídos do direito à cidade. No Brasil, o urbanismo fugiu à política e se travestiu de pura técnica de controle dos problemas produzidos pela disfunção urbana. Entre nós, o urbanismo emudeceu a cidade e se revestiu de uma forma de dominação fundada exclusivamente na técnica. (PECHMAN, 2002, p.17).
\end{abstract}

No caso brasileiro, o urbanismo conservador consolidou uma forma de pensar e fazer a cidade onde os mecanismos e instrumentos de planejamento tais como: Planos Diretores, Leis de Zoneamento Urbano, Código de Obras etc., legitimaram e legitimam juridicamente práticas segregadoras uma vez que há um nítido jogo de interesses na gestão da cidade beneficiando segmentos de classe de parcelas do território. Por exemplo, na análise do papel do zoneamento urbano na estruturação das cidades se estabelece a necessidade de irmos mais além, pensando o papel desse instrumento em processos de segregação socioespacial e exclusão social, definindo parâmetros urbanísticos, densidades e assim fragmentando a cidade e suas classes sociais. Utilizando uma expressão atual "cada um no seu quadrado", com base em determinados parâmetros urbanísticos se consegue separar intencionalmente as diferentes classes sociais no espaço consolidando os espaços de ricos e de pobres e assim a segregação urbana.

Embora a segregação socioespacial não ser um fenômeno novo ao longo da história do urbanismo, tem sido acentuada particularmente na segunda metade do século XX. Esse entendimento precisa ser feito à luz da relação entre urbanização e os mecanismos de reprodução do capital, e com as mudanças verificadas na economia e na sociedade sob a globalização. Algumas abordagens analíticas da teoria urbana buscam entender os 
determinantes centrais na conformação de padrões de segregação espacial. Jean Lojkine (1981) foi um dos teóricos que privilegiou em suas análises o papel do Estado como agente central na configuração do urbano. Sua abordagem sobre a segregação urbana é entendida como um mecanismo do Estado para garantir a adequada reprodução do capital e da força de trabalho. Dois elementos são centrais na sua análise: o primeiro refere-se ao papel dos proprietários fundiários na definição da renda da terra, e o segundo ao papel da política estatal como mecanismo legitimador de práticas segregadoras. No primeiro caso revela o papel dos proprietários fundiários urbanos como um dos detentores e controladores da ocupação e formulação do preço da terra urbana, mostrando a relação direta existente entre o papel da renda fundiária e a segregação urbana. Na outra vertente o papel desempenhado pela política estatal, no qual a planificação urbana serve como instrumento de intervenção no espaço, mas que, longe de democratizar o acesso aos meios de consumo coletivos, ao contrário, promove sua elitização. Esse se constitui de um forte mecanismo para a consolidação de um padrão segregativo. Para (LOJKINE, 1981) a política urbana sob o capitalismo monopolista não consiste em uma verdadeira planificação, mas reveste-se para atender outra lógica: à da segregação social. $\mathrm{O}$ Estado atua como gestor e regulador do acesso aos meios de consumo coletivos pelas diferentes classes e frações de classe, conforme sua renda, posição social, econômica e política. $\mathrm{O}$ acesso desigual aos meios de consumo coletivos (equipamentos urbanos e infraestrutura) "entrava a socialização do espaço urbano", configurando-se em um padrão de uso e ocupação do solo seletivo (LOJKINE, 1981). Ainda de acordo com este autor a relação direta entre política estatal urbana x segregação espacial é que existe uma estreita relação entre planos e práticas, pois na concepção dos planos está implícito à lógica social que os produziu, e desse modo os planos não são menos segregativos que as práticas.

Nessa mesma linha de raciocínio a análise de (SANTOS, 1994) converge para o papel do Estado e da legislação urbana. A cidade produto social apropriada privativamente é resultado de uma socialização capitalista. Socialização porque os denominados capitais comuns, de meios de consumo coletivo não são produzidos por capitais individuais, mas pelo Estado. Capitalista, pois os beneficiários não são a coletividade, mas uma minoria, segundo uma hierarquia de poder (econômico, político).

Uma das vias dessa apropriação privada seletiva se efetiva através da produção de uma segregação no espaço das classes sociais e sua legitimação pela via da legislação urbana. Ainda considerando o Estado na definição das políticas urbanas, este tem o papel de regular o conflito social pela apropriação da cidade, entretanto sua atuação não é neutra. Por exemplo, para (SALAS e CASTRO, 1993), no que se refere às políticas urbanas de habitação é notório o impacto dessas políticas na estruturação urbana e em padrões de segregação. Nessa mesma perspectiva analítica (COSTA, 1997) faz o questionamento do modelo de Estado capitalista existente e que reproduz espaços urbanos socioespaciais diferenciados. Esse entendimento conduz a uma análise que faz repensar o modelo de Estado que está colocado para a sociedade. Para o autor independente do período histórico, sob a égide do capitalismo, o que se tem são práticas e intenções que não rompem com uma estrutura social, política e econômica calcada, ainda, na conservação do status quo. "É imprescindível (re)pensar a participação do Estado no conjunto das práticas sociais voltadas para o enfrentamento das várias dimensões da exclusão, caracterizada pela não participação de uma parcela significativa da população na partilha do excedente gerado pelo modelo econômico atual." (pg. 1433-1434). Por sua vez para (CARLOS, 1996) "essa é a manifestação espacial das tendências de aprofundamento cada vez maior da divisão espacial do trabalho na produção do espaço urbano contemporâneo, na eliminação das fronteiras entre os Estados e na generalização do mundo da mercadoria”. (pg.191)

Com bases nestes autores pode-se concluir que os determinantes econômicos, políticos e ideológicos são centrais para entender a segregação. Nessa perspectiva de análise, uma teoria social do espaço e do urbano passa, necessariamente, por uma teoria da estrutura social. É necessário entender os elementos determinantes, os processos e as relações que estão no bojo da 
estrutura social sob a lógica capitalista. Nessa abordagem encontram-se as reflexões teóricas de (CASTELLS, 2000) que a partir de uma teoria do espaço urbano baseado no método estruturalista de análise partiu dos determinantes EPI (econômicos, políticos e ideológicos). Segundo ele, "analisar o espaço enquanto expressão da estrutura social resulta, consequentemente, em estudar sua modelagem pelos elementos do sistema econômico, do sistema político e do sistema ideológico, bem como pelas combinações e práticas sociais que decorrem dele" (p. 193).

Suas principais contribuições no esforço de análise do fenômeno da segregação urbana nas sociedades capitalistas podem ser apreendidas nos seguintes aspectos: o primeiro remete ao seu esforço de conceituação e o segundo remete a elaboração de um entendimento da estruturação do social sobre o espacial, ou seja, o espaço reflete as formas de produção e distribuição desigual dos produtos entre os sujeitos, o que está relacionado diretamente à diferenciação das classes no interior da sociedade. Portanto, a segregação está relacionada ao acesso desigual que têm as diferentes classes sociais ao espaço urbano, e a separação dessas classes no espaço. Entretanto, deixa claro que esse acesso desigual não se dá em função somente da estratificação social, mas de determinações mais gerais ligadas ao modo de produção e estruturação social. Assim para o autor a segregação urbana relaciona-se a alguns aspectos determinantes: em primeiro lugar é necessário entender as características da população, entender como se dá a estratificação social nas sociedades urbanas capitalistas contemporâneas e sua distribuição espacial. Seu nível de renda, seu status profissional, nível de instrução, de filiação étnica, etc., são determinantes na distribuição dos locais de residências. E o que (CASTELLS, 2000) denomina "estratificação urbana" corresponde ao sistema de estratificação social (ou sistema de distribuição dos produtos entre os indivíduos e os grupos) e, nos casos em que a distância social tem uma expressão espacial forte de "segregação urbana". Sob esse enfoque a segregação é apreendida sob uma perspectiva estruturalista havendo a interação dos condicionantes econômicos, políticos e ideológicos. Outro aspecto relevante que merece ser mencionado é que o autor foi um dos primeiros teóricos que buscou um esforço quanto a uma precisão conceitual da segregação urbana. Assim o conceito de segregação é definido como:

[...] a tendência à organização do espaço em zonas de forte homogeneidade social interna e com intensa disparidade social entre elas, sendo esta disparidade compreendida não só em termos de diferença, como também de hierarquia. (CASTELLS, 2000, p. 250, grifo do autor)

Outro autor (BRUN,1994) também se ocupou em aprofundar a reflexão sobre a segregação socioespacial do ponto de vista conceitual. Afirma que, embora o emprego desse conceito seja muito vasto, no sentido restrito inclui claramente a ideia de discriminação inclusive a origem semântica do conceito de segregação socioespacial contém a ideia de discriminação. Dessa forma a segregação designa uma prática voluntária um ator responsável, sendo essa definição ligada a uma prática deliberada de relegação de uma fração da população ao afastamento de zonas de moradia ocupadas pelas categorias mais favorecidas. Somam-se a essa característica mais dois elementos: uma forte especificidade social e uma fronteira espacial. Essa fronteira espacial tem o papel de proteger os habitantes de certas zonas privilegiadas do mundo exterior, ao mesmo tempo, que possibilita o isolamento dessa população. Um dos exemplos mais emblemáticos nas cidades contemporâneas são os condomínios fechados.

Sobre a aplicação do conceito de segregação socioespacial no sentido amplo e restrito SPOSITO destaca que no primeiro caso o conceito é aplicado no sentido de:

[...] afastamento e isolamento, referindo-se a formas de expressão, no 
nível espacial, de um processo de diferenciação social, ou mesmo de acentuação da divisão social do espaço no interior da cidade, sem que necessariamente tenham se deliberado mecanismos de exclusão voluntária (embora isso também ocorra), como decorrência de práticas de discriminação (SPOSITO, 1996, p. 72).

E no sentido restrito é claro o sentido de discriminação, sendo os loteamentos e condomínios fechados a melhor expressão espacial dessa noção.

A percepção dessa clareza conceitual também foi assinalada por (LEFEBVRE, 2002; 1991a) quando destacou a confusão que existe entre os termos diferença, distinção, separação e segregação. A diferenciação pressupõe relações, proximidade, contradições. A segregação e a separação, por sua vez, rompem as relações, o contraditório, o diferente. Fez uma crítica contundente ao modelo de cidade que surgiu com o desenvolvimento do industrialismo - a cidade capitalista e o papel do urbanismo na instituição e legitimação desse modelo. Suas críticas e reflexões teóricas estão centradas nos aspectos que podemos denominar de desencadeadores de um novo modo de vida urbana. O espaço urbano na cidade capitalista passou a ser mediado pelo valor de troca em oposição ao seu valor de uso. Encontra-se aí um dos pontos centrais de sua contribuição teórica sobre o urbano na conformação do modelo de cidade capitalista, e que segundo ele substituiu o sentido do habitar urbano para o de habitat.

O habitar a cidade contém o sentido da convivência, do cotidiano, dos espaços simbólicos, da memória dos lugares, por sua vez, o habitat reduziu o sentido da cidade a uma vida regulada pelas instituições e o Estado. O espaço enquanto valor de uso passou a valor de troca, o lugar cedeu espaço a territórios demarcados e separados. O espontaneísmo cedeu lugar ao pragmatismo, ao racionalismo. Sua crítica ao urbanismo moderno vem nesse sentido, ou seja, este urbanismo quis tomar para si o sentido da cidade conferindo-lhe uma ordem e projetando uma cidade ideal. Nessa acepção de cidade "as segregações que destroem morfologicamente a cidade e que ameaçam a vida urbana não podem ser tomadas por efeito nem de acasos, nem de conjunturas locais" (LEFEBVRE, 1991, p. 95).

Iremos encontrar em sua abordagem três aspectos nos quais se reveste a segregação: "espontâneo (proveniente das rendas e das ideologias) - voluntário (estabelecendo espaços separados) - programado (sob o pretexto de arrumação e de plano). A segregação separa as diferenças propõe uma hierarquia (de classes sociais quanto aos seus extratos de renda, à sua raça, à sua etnia, seus valores religiosos), criando os guetos. Para o autor o verdadeiro sentido da cidade está nas diferenças, nas contradições e, a partir do momento que o urbanismo vem combater essas diferenças através de uma proposta homogeneizadora do espaço, está ao mesmo tempo combatendo o verdadeiro sentido da vida urbana. Mas para o autor estas estratégias denominadas de classe, visto que visam favorecer determinados setores e ou segmentos sociais (econômicos, políticos, sociais), possui uma lógica, ou seja, a lógica da dominação.

Nessa perspectiva de análise concordamos que a ciência urbanística emerge como uma estratégia das classes dominantes, também representadas pelo Estado, para um efetivo controle das classes sociais, aliada a uma maior eficiência da máquina urbana no sentido de favorecer uma reprodução do capital. Neste sentido na cidade capitalista sob a égide da razão e do urbanismo a vida cotidiana foi:

[...] decupada em fragmentos: trabalho, transporte, vida privada, lazeres. A separação analítica os isolou como ingredientes e elementos químicos, como matérias brutas (quando na verdade resultam de uma longa história e implicam uma apropriação da materialidade). (...) Eis o ser humano desmembrado, dissociado. (LEFEBVRE, 1991, p. 97). 
Para o autor a segregação precisa ser entendida também pelas razões teóricas e políticas. No primeiro caso o próprio pensamento costuma separar, no segundo caso, as estratégias de classes visam sempre a segregação.

Outro autor que tem pautado seus estudos no entendimento da dinâmica da segregação é (VILLAÇA, 1998), procurando entender à luz da realidade das cidades brasileiras para quem a segregação espacial é um aspecto fundamental para a compreensão das estruturas espaciais de nossas cidades. Para o autor por ser um processo histórico será nas bases da sociedade, da economia e da política que se pode desvendar seus objetivos. Se para (CASTELLS, 2000) a segregação urbana é o reflexo do social sobre o espacial, visto que o espaço é expressão da estrutura social estudando-a pelo sistema econômico, político e ideológico, (VILLAÇA,1998) defende por sua vez que a segregação urbana é o efeito do espacial sobre o social, pois é através do controle do espaço que a classe dominante controla outros segmentos sociais e, desse mesmo modo, controla o uso e consumo do espaço urbano. É por meio do domínio do espaço que se efetiva o domínio de determinadas parcelas da sociedade e a apropriação do trabalho coletivo. Desse modo afirma que:

[...] é necessária uma certa geografia, uma certa configuração espacial (a segregação) para viabilizar a dominação através do espaço. Sem essa configuração, seriam talvez impossíveis - ou extremamente difíceis - a dominação e a desigual apropriação dos frutos do trabalho despendido na produção do espaço. (...) É por meio da segregação que a classe dominante controla o espaço urbano sujeitando-o aos seus interesses (VILLAÇA, 1998, p. 359 - grifo do autor)

Para (VILLAÇA,2000) a categoria central para explicar a segregação urbana nas cidades brasileiras é a localização, que passa pela compreensão do espaço urbano não somente como espaço de produção, mas, sobretudo, como espaço de consumo. Sua ideia está consolidada na premissa de que a localização desempenha papel de destaque, pois mais do que nunca existe uma disputa constante pelas melhores localizações na cidade. Estão mais bem situados na cidade aqueles que possuem as melhores localizações, seja para fins de reprodução do capital (produção, consumo e distribuição), seja para fins de reprodução da força de trabalho (moradia, lazer, compras e outros consumos de modo geral). Portanto, a localização nessa abordagem funciona como "uma disputa pela otimização (não necessariamente minimização) dos gastos de tempo e energia. Assim a segregação e o controle do tempo de deslocamento dos indivíduos que ela possibilita são decisivos nessa disputa. (pg. 333)

Das abordagens até aqui apresentadas destacamos as abordagens teóricas que enfatizam o Estado, o mercado fundiário e a sociedade (sistema econômico, político e ideológico) como determinantes centrais na análise da segregação. A essas abordagens acrescentamos a que faz uma leitura do entendimento do mercado imobiliário nesse processo. Nessa linha de pensamento destacam-se as pesquisas desenvolvidas por (SMOLKA,1992), para quem existe uma relação direta entre segregação e o papel da dinâmica imobiliária. A escala privilegiada de suas análises é a metrópole, no caso, o Rio de Janeiro, mas essa abordagem se aplica também a outras dimensões escalares, visto que estas lógicas não são exclusivas das metrópoles.

Esses autores deixaram expressivas contribuições para esse debate que hoje, mais do que antes, tem tomado visibilidade crescente a partir de diversos recortes analíticos no entendimento das cidades capitalistas contemporâneas. Se por um lado processos de segregação socioespacial tem se ampliado nas cidades contemporâneas, não podemos deixar de entender também a ampliação dos processos de exclusão inerentes ao modo de produção capitalista. A seguir é apresentado com base em alguns autores este debate, chamando atenção para a amplitude deste conceito e como podemos entende-los à luz da reprodução das cidades. 


\section{EXCLUSÃO SOCIAL, TERRITORIAL E URBANÍSTICA: APROXIMAÇÕES CONCEITUAIS}

Os estudos e debates sobre processos de exclusão social têm ocupado a agenda em diversos campos do conhecimento, notadamente das ciências humanas e sociais. Não é um processo novo exclusivo de países pobres, mas presente também nos países do primeiro mundo resultado das políticas econômicas neoliberais no início da década de 1980. Por ser uma temática ampla e complexa, e que está longe de se chegar a um consenso quanto a um conceito único, a proposta desse artigo é apresentar esta reflexão tendo como premissa alguns teóricos, e como podemos adequá-las aos estudos das ciências humanas, particularmente na geografia urbana e sua articulação com os processos de segregação socioespacial.

Comecemos por concordar com os teóricos que discutem esta temática afirmando haver uma confusão generalizada entre os conceitos de exclusão e pobreza como adequadamente salientaram (ESCOREL, 1999; COSTA, 2001; VÉRAS et al., 1999; GORDON e TOWNSEN, 2000).

Para (COSTA, 2001) por exemplo, o conceito de pobreza de origem britânica, "consiste numa situação dinâmica de privação, por falta de recursos. Ambas essas condições - privação e falta de recursos - são necessárias à definição" (pg.19). Para o autor, podemos relacionar este conceito de pobreza com a situação da exclusão social, uma vez que os pobres são excluídos de alguns dos sistemas sociais básicos.

Mas o conceito de exclusão social de origem francesa é enfatizado em uma perspectiva mais ampla que somente a falta de recursos. Trata-se também e, principalmente, das sucessivas perdas que o indivíduo sofre não somente relacionado com o mercado de trabalho, mas também a perda familiar, afetiva, de amizade e inclusive territorial. A noção francesa enfatiza a ruptura que ocorre do indivíduo com a sociedade, a perda da sua inserção na sociedade, assim como a perda dos laços sociais e até mesmo de identidade social e individual. Neste sentido segundo este autor a exclusão social está relacionada a noções de cidadania, de direitos humanos e democracia, traduzidas pelo acesso a um conjunto de sistemas sociais básicos do mundo do trabalho e da vida social mais ampla. Continuando suas ideias a exclusão social deve ser entendida como exclusões sociais.

Por sua vez para (PAUGAM,1999) a exclusão incorpora três dimensões: o de trajetória, o de identidade e de território. O de trajetória recupera a ideia que a exclusão é um processo, portanto, entendida como algo dinâmico e não estático. O de identidade, pois no processo de exclusão há uma interiorização de aspectos negativos (discriminação racial, estigmatizar, identidade negativa) e o de território que remete em como o processo de exclusão pode estar concentrado em determinadas parcelas do espaço, de territórios socialmente excluídos do conjunto da cidade.

O destaque para a dimensão territorial da exclusão nos remete a duas condições desse tipo de processo social. A primeira refere-se, sobretudo, a perda do sentimento de pertencer a um lugar, condição essencial desde o nascimento da humanidade para o senso de localização e pertencimento do indivíduo no espaço em que vive e em sua articulação com a sociedade. $\mathrm{O}$ excluído perde seu referencial geográfico e simbólico. Ele está em nenhum lugar e em todos os lugares ao mesmo tempo, pois sua condição de mobilidade constante não permite a criação de vínculos de qualquer ordem com o território.

O reconhecimento da relevância do domínio territorial no estudo da exclusão social é recente como assevera (COSTA,1997), e tem a ver com o fato de existirem certas situações em que a exclusão diz respeito não apenas as pessoas e famílias, mas a todo um território, tanto na perspectiva individual, ou seja, do indivíduo estar excluído do acesso à terra, moradia, e ou até mesmo a certos lugares na cidade. Ou mesmo a exclusão territorial no sentido de uma perspectiva geográfica mais ampla da cidade, como na escala de um bairro, a de uma rua, por 
exemplo. Essa dimensão da exclusão remete também a escala do lugar, pois quando falamos de perda estamos nos referindo a relação do indivíduo com o meio em que está inserido, e a categoria lugar representa esta parcela do espaço vivido, sentido, da cotidianidade e da história de cada um.

Desse modo pode-se ratificar que o processo de exclusão social reforça o de segregação espacial e vice-versa, como um processo dialético consolidando, por sua vez, uma situação de exclusão em outras esferas.

Em uma outra abordagem das dimensões da exclusão (MARICATO, 1996 e ROLNIK, 1999), chamam atenção da consolidação de processos de informalidade/irregularidade no uso e ocupação do solo urbano às margens das normas urbanísticas, ou seja, que não correspondem na prática ao que determina os instrumentos urbanísticos de regulação do espaço urbano, tais como as Leis do Plano Diretor, as Leis de Uso e Ocupação do Solo Urbano, de Parcelamento do Solo Urbano e Código de Obras ou de Posturas. Com isso se consolida um padrão de urbanização seletivo e excludente, uma vez que se instauram dois padrões paralelos de reprodução da cidade: por um lado uma parcela da cidade que está dentro dos padrões que a legislação urbanística determina, e por outro que se constrói a revelia da lei.

Para (MARICATO,1996) as diversas formas que reveste a segregação socioespacial e exclusão social estão representadas pela ilegalidade nas condições de moradia, ilegalidade nas relações de trabalho, ilegalidade na ação da política ou desconhecimento de tribunais para resolução de conflitos, além da impunidade, ilegalidade em relação a propriedade da terra, exclusão econômica, social, cultural, ambiental, etc. A condição de permanente irregularidade urbanística que vive uma grande parcela da população, as mantêm excluídas de um conjunto de parâmetros legais que possibilitam viver em condições mínimas de habitabilidade tais como infraestrutura, equipamentos e serviços urbanos, e isso quer dizer o direito ao conjunto de benefícios urbanos. Ao se negar esse direito é que atribuímos o conceito de exclusão urbanística.

Esse entendimento nos reporta a análise da legislação urbanística e seu papel em padrões de segregação socioespacial como bem apontou (LEFEBVRE,1991) em sua crítica ao planejamento estatal, estabelecendo a relação entre a norma e o fato, mostrando que existe um distanciamento no que está estabelecido legalmente e a realidade.

\section{ALGUMAS CONSIDERAÇÕES SOBRE ESTA REFLEXÃO}

A manifestação no espaço geográfico de fenômenos de segregação espacial remonta a própria história das cidades. A instituição de uma sociedade de classes foi fundamental para a instituição das cidades e do fenômeno urbano. Entretanto, as desigualdades sociais e econômicas refletidas através de uma estratificação social resultou, igualmente, em fenômenos em que esta desigualdade de classes era expressa no espaço geográfico configurando uma segregação socioespacial.

Ao longo do desenvolvimento da sociedade de classes e da própria urbanização este fenômeno ganhou força, com destaque para as sociedades capitalistas em que a terra é uma mercadoria gerando grandes disputas. Este texto procurou resgatar as ideias dos principais teóricos expoentes da denominada "nova sociologia urbana" que ganhou expressão na academia francesa em meados de 1960 em diante e se expandiu ao redor do mundo, e demais autores em que se faz premente a análise das dinâmicas intraurbanas a partir do fundamento marxista.

Para isso privilegiou-se autores como (LEFEBVRE, 2002,1991a; CASTELLS, 2000; LOJKINE, 1981) que foram os precursores e que estabeleceram uma nova perspectiva analítica do espaço urbano contrapondo as ideias até então em voga das teorias da Escola de Chicago. Entender a dinâmica urbana, como por exemplo, processos de segregação requer entender as lógicas que regem o Modo Capitalista de Produção. 
Trouxemos para o texto teóricos que se ocuparam em analisar o papel do Estado como agente central de processos de segregação tais como: (LOJKINE,1981; LEFEBVRE, 2000, 1991a; CASTELLS, 2000; SALAS e CASTRO, 1993; COSTA, 1997) entre outros. Para eles o Estado não é neutro. Embora na teoria sua função deva ser o de regulador dos interesses de diversos atores sociais e econômicos na sociedade, na prática, sua função é de defender os interesses das classes dominantes por meio de seus instrumentos de regulação: sistema jurídico, legislativo e econômico. No que tange a reflexão proposta nesse texto, dos processos resultantes de uma reprodução e acesso desigual das cidades fica nítido este papel. Para LOJKINE por exemplo, a segregação espacial reflete este jogo de interesses que se dá no âmbito do Estado/poder público sendo determinante nas diretrizes de política urbana. As leis urbanísticas de uso e ocupação do solo urbano são produtos de uma disputa de interesses de classe no qual o sistema jurídico/legislativo efetiva através das leis, defendendo interesses de grupos sociais/econômicos em detrimento do interesse público, ideias também apresentadas por (LEFEBVRE, 2000, 1991a; COSTA, 1997; SANTOS,1994).

Para (VILLAÇA, 1998) a categoria "localização" é central para se entender os processos segregativos. Partindo das principais metrópoles brasileiras o autor apresenta como se estabeleceu diferentes padrões de segregação socioespacial. Já (SMOLKA,1992) concentra suas análises em como o mercado imobiliário atua em processos segregativos ao estabelecer parcelas da cidade para a oferta de seu produto "moradia" para os diferentes níveis sociais, demarcando espaços de ricos e pobres e definindo junto com o poder público os processos de expansão urbana e de segregação.

Os autores apresentados no texto, nos remeteu a compreensão da multiplicidade e complexidade da adequada aplicação do conceito de exclusão social. Que são múltiplas as variáveis que interferem e definem esse processo. Alguns teóricos como (ESCOREL, 1999; COSTA, 2001; VÉRAS et al., 1999; GORDON e TOWNSEN, 2000, PAUGAM,1999) em suas análises se ocupam de revelar a variedade de interpretações em que este conceito é utilizado. Se por um lado temos muitos estudos sobre exclusão social e suas múltiplas manifestações na sociedade contemporânea, (MARICATO, 1996 e ROLNIK, 1999) apontam no texto a importância da ampliação dessa análise incorporando as esferas territorial e urbanística. Revela como ainda é pouco explorado os conceitos de exclusão territorial e exclusão urbanística. A aplicação desses conceitos em países subdesenvolvidos em que os desníveis socioeconômicos são abissais como no Brasil, são centrais para uma análise mais ampla desse fenômeno, caso contrário, incorremos no risco de uma interpretação superficial. Nesse sentido a importância de se incorporar nas análises da exclusão a categoria território e a categoria urbanística.

Não foi objetivo desse artigo abordar como se dá os processos de segregação e exclusão no Brasil, mas apresentar autores que se ocuparam e se ocupam de explicar estes processos à luz da corrente marxista do pensamento sociológico contemporâneo. Contudo cabe aqui destacar que ao se considerar o marxismo como base analítica de interpretação da realidade tem que ter em mente as peculiaridades da sociedade a qual estes fenômenos/processos se estabelecem, pois, são produto e ao mesmo tempo reflexo do modelo econômico e social imposto a sociedade. No caso do Brasil um país subdesenvolvido, detentor ainda de uma forte herança oligárquica, escravocrata, baseado em uma economia agroexportadora de produtos primários, estes fenômenos são ainda mais expressivos.

O padrão de urbanização das cidades brasileiras centrada no modelo centro x periferia, foi o que subsidiou os estudos da segregação urbana no Brasil revelando um modelo com acentuada fragmentação do seu tecido urbano. Por um lado, se efetiva uma expansão urbana para as áreas periféricas, escassas de infraestrutura e equipamentos urbanos com predomínio de uma população de baixa renda. Por outro lado, áreas bem localizadas dotadas de infraestrutura e serviços ocupadas por uma população de rendas alta e média. Este padrão centro x periferia estabeleceu os estudos de segregação brasileira ao longo dos anos. Contudo atualmente é preciso relativizar as análises da segregação urbana com base neste padrão de urbanização, uma 
vez que novas lógicas e atores estão entrando em cena. Considerando a realidade das metrópoles brasileiras na atualidade, somente a título de exemplo podemos destacar a implantação dos novos padrões de moradia de alta renda representadas pelos condomínios fechados horizontais a partir da década de 1980, no qual ao se estabelecerem em áreas periféricas deslocam uma parte das classes sociais e suas demandas (em termos de serviços e equipamentos urbanos) para estas áreas. Até então a simples leitura desse padrão de urbanização no qual "os ricos estão nas áreas centrais e os pobres nas periferias", não mais se sustenta, devendo relativizar quando se trata da realidade brasileira. Daí a importância da relativização desses processos enquanto escala geográfica de análise (local, nacional e global). Não se aplica igualmente a todos os espaços e sociedades.

Este exercício reflexivo de revisão teórico/conceitual de estudiosos que se ocuparam e tem se ocupado com esta temática, revelou a complexidade de tais processos e a dificuldade de se estabelecer um conceito único. Colocou a necessidade de se pensar em um maior rigor teórico e conceitual quando de sua aplicação as realidades urbanas, desde uma escala global a uma escala local. Remeteu igualmente a pensar o sentido das cidades e as lógicas inerentes a sua produção e reprodução e o lugar dos indivíduos nesse processo. Se por um lado, tem-se políticas urbanas que acabam por consolidar padrões segregativos e excludentes, por outro lado, também se tem práticas que tem possibilitado a inclusão social e espacial dos indivíduos aos territórios/espaços da cidade. A produção e gestão urbana sob a lógica do capital que é o lucro, têm conformado cidades cada vez mais desiguais. Cabe a todos os profissionais que atuam com políticas urbanas revelar estas desigualdades, estudar e apontar diretrizes visando sociedades e cidades mais inclusivas e democráticas.

\section{REFERÊNCIAS}

BRUN, Jacques. Essai critique sur la notion de segrégation et sur son usage em géographie urbaine. In: La segregation dans la ville. Paris: Editions L'Harmattan, 1994. p. 21-57

CARLOS, Ana Fani Alessandri. A natureza do espaço fragmentado. In: SANTOS, Milton,SOUZA, Maria Adélia A.; SILVEIRA, Maria Laura. (orgs.) Território: globalização e fragmentação. São Paulo: Hucitec/ANPUR, 1996. p.191-197.

CASTELLS, Manuel. A questão urbana. São Paulo: Paz e Terra, 2000.

COSTA, Geraldo Magela. Exclusão socioespacial na era urbano-industrial: uma introdução ao tema. ENCONTRO NACIONAL DA ANPUR, 7, 1997, Recife. Anais... p.1421-1436.

CORRÊA, Roberto Lobato. O espaço urbano. São Paulo: Ática, 1989. (Série Princípios no.174)

ESCOREL, Sarah. Vidas ao léu: trajetórias de exclusão social. Rio de Janeiro: Fiocruz, 1999.

GORDON, David; TOWNSEND, Peter. Breadline Europe. Great Britain: Policy Press, 2000.

LEFEBVRE, Henri. O direito à cidade. São Paulo: Moraes, 1991.

LEFEBVRE, Henri. A revolução urbana. Belo Horizonte: Editora da UFMG, 2002.

LOJKINE, Jean. O Estado capitalista e a questão urbana. São Paulo: Martins Fontes, 1981.

MARICATO, Ermínia. Metrópole na periferia do capitalismo: ilegalidade, desigualdade e violência. Estudos Urbanos. São Paulo: Hucitec, 1996.

PAUGAM, Serge. Abordagem sociológica da exclusão. In: VÉRAS, Maura P. B.; SPOSATI, Aldaíza; KOWARICK, Lúcio. (Orgs.). Por uma sociologia da exclusão social: o debate com Serge Paugam. São Paulo: EDUC, 1999.

PECHMAN, Robert Moses. Cidades estreitamente vigiadas: o detetive e o urbanista. Rio de Janeiro: Casa da Palavra, 2002.

ROLNIK, Raquel. Regulação urbanística e exclusão territorial. São Paulo, Pólis, nº , 32, 1999. 
SANTOS, Milton. Por uma economia política da cidade: o caso de São Paulo. São Paulo: Hucitec, 1994.

SALAS, Minor Mora; CASTRO, Franklin Solano. Segregacion urbana: un acercamiento conceptual. Revista de Ciências Sociales, Costa Rica, no 61, p. 17-26, set, 1993.

SPOSITO, Maria Encarnação Beltrão. Reflexões sobre a natureza da segregação espacial. Revista de Geografia. Dourados: AGB, set/out/nov/dez, p. 71-85, 1996.

SMOLKA, Martin Oscar. Expulsando os pobres e redistribuindo os ricos: "dinâmica imobiliária" e segregação residencial na cidade do Rio de Janeiro. Revista Brasileira de Estudos de População, São Paulo, vol.9, nº1, p.03-21, jan/jul, 1992.

VÉRAS, Maura P. B.; SPOSATI, Aldaíza; KOWARICH, Lúcio. Por uma sociologia da exclusão social: o debate com Serge Paugam. São Paulo: EDUC, 1999.

VILLAÇA, Flávio. A segregação urbana. In: Espaço intra-urbano no Brasil. São Paulo: Studio Nobel: FAPESP: Lincoln Institute, 1998. 